\title{
JURISPRUDENCIA CONSTITUCIONAL EN MATERIA DE PROTECCIÓN DEL MEDIO AMBIENTE
}

(SEGUNDO SEMESTRE 2020)

\author{
CLARA EsteVE JoRdÀ \\ Investigadora Predoctoral Contratada Martí i Franquès \\ Universitat Rovira i Virgili
}


Sumario: 1. Introducción. 2. Protección y bienestar animal. ¿Tienen los animales dignidad? 3. Límites a la potestad tributaria autonómica: prohibición de doble imposición sobre el mismo hecho imponible. 4. Competencias sobre montes: potestad de deslinde. 5. Uso de bolsas de plástico: prevalencia de competencias en medio ambiente frente a la planificación económica.

\section{INTRODUCCIÓN}

No cabe duda de que el año 2020 ha estado marcado por la pandemia del coronavirus, y que ello ha tenido múltiples consecuencias, sin ser el sector judicial una excepción. En el ámbito constitucional hay que tener en cuenta que, por primera vez desde su instauración en 1979, el órgano de garantías constitucionales acordó dejar en suspenso los plazos procesales y administrativos durante la vigencia del estado de alarma declarado por el Real Decreto 463/2020, de 14 de marzo, y sus eventuales prórrogas ${ }^{1}$. Por consiguiente, se paralizó el vencimiento de las actuaciones para las partes, desde la segunda quincena de marzo hasta la primera de junio de 2020 , en todo el Estado español. Si bien el Tribunal Constitucional no interrumpió su funcionamiento durante el periodo de confinamiento oficial, lo cierto es que no se dictó ninguna sentencia entre el 9 de marzo y el 15 de junio de este año ${ }^{2}$. A partir de entonces, sí encontramos fallos de este tribunal, entre ellos, sobre cuestiones de medio ambiente.

Vivimos en un tiempo histórico y seguramente, tras esto, ya nada volverá a ser igual. Es probable que el impacto del coronavirus también se vea reflejado, en mayor o menor medida, en las próximas sentencias del garante de la

\footnotetext{
${ }^{1}$ Acuerdo de 16 de marzo de 2020, del Pleno del Tribunal Constitucional, en relación con la suspensión de los plazos procesales y administrativos durante la vigencia del Real Decreto 463/2020, de 14 de marzo. Disposición 3805 del BOE núm. 71 de 2020.

Acuerdo de 6 de mayo de 2020, del Pleno del Tribunal Constitucional, sobre cómputo de los plazos procesales y administrativos que fueron suspendidos por Acuerdo de 16 de marzo de 2020, durante la vigencia del Real Decreto 463/2020, de 14 de marzo. Disposición 4882 del BOE núm. 128 de 2020.

${ }^{2}$ Durante el período oficial de confinamiento, el TC sí que registró otro tipo de resoluciones, como autos, acuerdos e informes jurisdiccionales. Además, llegó a realizar un Pleno no presencial, es decir, por medios telemáticos, con fecha 6 de mayo de 2020. Sin embargo, según El País, el Tribunal no realizó más plenos en sesión virtual debido al riesgo de ataques informáticos y a las dificultades de realizar las deliberaciones sin la asistencia personal de los miembros de la institución ni la mecánica habitual de los debates presenciales. Véase: José María Brunet, "EI Constitucional alega temor a un 'hackeo' y decide paralizar los plenos", 16 de mayo de 2020 en El País <https://elpais.com/espana/2020-05-15/el-constitucional-alega-temor-a-un-hackeo-ydecide-paralizar-los-plenos.html> [Última consulta, 17 de septiembre de 2020].
} 
Constitución, en múltiples materias. No obstante, la protección del medio ambiente no parece ser por el momento el tema de mayor preocupación, ni antes del COVID-19, ni tampoco ahora. Posiblemente habrá que esperar todavía un tiempo, pues lo que se observa es una postergación generalizada de las cuestiones medioambientales, para atender a lo urgente. Es evidente que el asunto científico-sanitario prima en las circunstancias actuales, sin embargo no debe ni puede ser el único. La lucha contra el cambio climático permanece como un difícil reto del siglo XXI, que no puede ser retrasado. Al fin y al cabo, la crisis del coronavirus enlaza con la presente crisis climática y la del sistema capitalista, pone de manifiesto las carencias estructurales del sistema, e invita a la reflexión sobre la forma de relacionarnos en sociedad y con la naturaleza. De momento, celebremos que en tiempos de pandemia, el Tribunal Constitucional sigue dictando sentencias sobre cuestiones medioambientales.

\section{PROTECCIÓN Y BIENESTAR ANIMAL. ¿TIENEN LOS ANIMALES DIGNIDAD?}

En la crónica de jurisprudencia constitucional ambiental del $1 \mathrm{r}$ semestre del año 2020, que precede a ésta, se analizaba, en el apartado 3, la impugnación de la Ley del Parlamento de La Rioja 6/2018, de 26 de noviembre, de protección de los animales en la Comunidad Autónoma de La Rioja. En aquella ocasión, era el Consejo de Gobierno de La Rioja (por aquel entonces, el Partido Popular) quien interponía el recurso de inconstitucionalidad. Sin embargo, el recurso no fructificó. La constitucionalidad de la ley riojana no se pudo entrar a valorar, dado que el Tribunal Constitucional declaró la inadmisión del recurso, por falta de legitimación activa de su promotor.

En aquel comentario señalamos la posibilidad de esperar, en un futuro, a que otro promotor interpusiera un recurso de inconstitucionalidad análogo sobre la misma ley. $Y$ esto es lo que precisamente ha ocurrido. Esta vez es el grupo parlamentario Popular del Senado quien interpone un recurso de inconstitucionalidad, en relación con diversos preceptos de la Ley autonómica de la Rioja sobre protección animal. En este caso, que se resuelve mediante la STC 81/2020, de 15 de julio, se quiso adherir de nuevo el letrado de la Comunidad Autónoma de La Rioja, en representación y defensa del Consejo de 
Gobierno de La Rioja. Pero, como se verá, una vez más el Tribunal Constitucional le tumba el derecho a participar en el recurso, al carecer el ejecutivo de La Rioja de legitimación activa para recurrir una ley autonómica.

Pues bien, procedamos a analizar la STC 81/2020, de 15 de julio. Con fecha 26 de febrero de 2019, un grupo de más de cincuenta miembros del grupo parlamentario Popular del Senado registró un recurso de inconstitucionalidad, sosteniendo la vulneración de diversos preceptos de la Constitución, por un lado, en el plano del orden de distribución de competencias, y por el otro, en sentido material. El Alto Tribunal, como suele hacer en los casos en que se alegan tanto la invasión de competencias estatales como la vulneración de principios constitucionales y de libertades y derechos fundamentales, establece como orden de enjuiciamiento, primero las infracciones competenciales y posteriormente, las sustantivas.

No puede iniciarse el análisis del conflicto competencial sin una breve observación sobre el objetivo del grupo parlamentario Popular. Lo cierto es que la invasión general de competencias exclusivas del Estado que se alega, en realidad evidencia una tensión entre la protección del medio ambiente, concretizada en la salvaguarda de los animales, y el desarrollo económico, especialmente en el ámbito privado. El grupo recurrente observa, en este sentido una incompatibilidad entre la protección animal y la actividad económica de la sociedad española — para el caso concreto, la riojana — priorizando, por ejemplo, actividades humanas como la tauromaquia o la caza, por encima del bienestar de los animales. Ello implica la expresión de una ideología, más o menos pronunciada, que jerarquiza y expresa un mayor interés por ciertas prácticas tradicionales con un rendimiento considerable en el Estado español - aunque no exentas de polémica - por encima de una creciente preocupación, en la sociedad española actual, ante el maltrato, el sufrimiento y el abandono animal. No menos importante resulta el hecho de que, durante la pendencia del recurso de inconstitucionalidad, algunos de los preceptos impugnados de la Ley 6/2018 quedaron modificados por la Ley del Parlamento de la Rioja 2/2020, de 30 de enero, de medidas fiscales y administrativas para el año 2020. Ello es especialmente relevante en la sentencia, puesto que, como se verá, muchos preceptos quedan salvados por tales reformas, mediante la pérdida de objeto. 
En primer lugar, el Tribunal Constitucional entra a examinar la definición de maltrato animal de la Ley 6/2018, ya que, según la parte recurrente, se aparta de las leyes estatales. Los preceptos de la ley riojana prohíben que el maltrato se ejerza dolosamente, injustificadamente, causando sufrimientos o daños innecesarios. De este modo, la ley riojana vulneraría la legislación estatal básica sobre bienestar animal, porque el legislador estatal sí que considera aceptables diversas prácticas legítimas con animales (explotaciones ganaderas, sacrificio para el consumo humano, experimentación científica, etc.), cuando el fin lo justifica. El Tribunal Constitucional, al respecto, resuelve la pérdida de objeto sobre este precepto, ya que la Ley riojana de medidas fiscales posterior, introdujo el matiz de que se debía entender por maltrato animal "toda conducta, tanto por acción como por omisión, mediante la cual se inflige a un animal dolor o sufrimiento inúti'?. El Tribunal Constitucional remata el fundamento señalando que:

"Es claro que la actual definición de maltrato animal del art. 5 o) de la Ley 6/2018, coincidente con la que se contiene en la normativa básica, no concierne a los supuestos de actividades legítimas en relación con los animales de producción: reproducción, crianza y sacrificio para el consumo humano, obtención de alimentos o productos de origen animal, utilización para el trabajo agropecuario, o para cualquier otro uso industrial o fin comercial o lucrativo; tampoco respecto de animales utilizados para experimentación y otros fines científicos, incluida la docencia, que puedan suponer algún tipo de daño, sufrimiento o dolor para estos animales. Esas actividades lícitas, tal como señalan las normas básicas y la propia ley autonómica impugnada, deberán llevarse a cabo de modo que se evite, en la medida de lo posible, causar sufrimientos o daños inútiles o injustificados a los animales. En consecuencia, tales actividades no podrán ser consideradas como infracciones graves del art. 54.6 de la Ley 6/2018 o muy graves del art. 55.1 de la misma ley" [FJ 5].

Evidenciándose, de este modo, que tanto la Constitución como la legislación estatal mantienen una clasificación de categorías de la especie animal. La jerarquía comprende, por un lado, los animales domésticos, es decir, con la finalidad de proporcionar compañía a las personas, a quienes se considera "de primera categoría", quienes no deben sufrir un maltrato inútil. Por otro lado, están 
los animales de producción, que serían los "de segunda categoría", es decir, los que el ser humano considera aptos para alcanzar sus objetivos de desarrollo económico. Estos últimos no reciben un maltrato inútil, porque los fines de dicho maltrato están justificados por el consumo y uso humano.

Asimismo, el grupo promotor entiende que la Ley 6/2018 se extralimita competencialmente, al regular relaciones jurídicas entre particulares, esto es, prohibiciones de donación, venta y cesión de animales, así como de filmación. El juez de la constitucionalidad, a este respecto, da la razón al recurrente, por cuanto los preceptos referidos inciden directamente en la regulación de la estructura de determinados contratos, tanto en el objeto como en la capacidad de contratar, que son la base de las obligaciones contractuales, de competencia exclusiva estatal "en todo caso". En consecuencia, diversos apartados $(8,10,11$, 12 y 14) del art. 7 de la ley 6/2018 son declarados inconstitucionales y nulos, al invadir la competencia exclusiva estatal en materia de legislación civil (art. 149.1.8 CE),

Del mismo modo, según el grupo del Senado que interpone el recurso, se estarían vulnerando las competencias exclusivas estatales en materia de planificación general de la actividad económica (art. 149.1.13 CE), fomento y coordinación general de la investigación científica y técnica (art. 149.1.15 CE), bases y coordinación general de la sanidad (art. 149.1.16 CE) y legislación básica sobre protección del medio ambiente (art. 149.1.1.23 CE). Concretamente se estarían vulnerando diversas y abundantes leyes y disposiciones estatales, que regulan la sanidad animal, el cuidado de los animales en su explotación, transporte, experimentación y sacrificio, la protección de los animales en las explotaciones ganaderas, en la experimentación y otros fines científicos, así como la protección de las gallinas ponedoras y de cerdos.

Algunos preceptos recurridos en este sentido quedan rechazados por el TC, debido a que el grupo recurrente olvida cumplir con la carga de identificar las concretas normas básicas con las que la ley riojana entraría en contradicción. Es el caso, por ejemplo, de la obligación de esterilización de determinados animales de compañía [FJ 7], y de la prohibición de usar perros como barrera para impedir el paso del ganado [FJ 8.b)]. Otros preceptos, al ser modificados por la citada Ley $2 / 2020$, de medidas fiscales y administrativas para el año 2020, no se entran 
a examinar por el Tribunal Constitucional, ya que pasan a ser compatibles con la legislación estatal básica con la nueva redacción y se produce la pérdida de objeto en cuanto a dichas tachas competenciales. Es ejemplo de ello la prohibición de mantener a los animales atados o encerrados permanentemente o en condiciones que les provoquen sufrimiento, que pasa a ceñirse solamente a los animales de compañía y, por tanto, exime a las gallinas ponedoras y los cerdos de dicha prohibición [FJ 8.a)]. También es el caso de la regulación del transporte de animales de compañía [FJ 9].

Por otro lado, en lo que atañe a las infracciones constitucionales de carácter material o sustantivo, la problemática se observa, en parte, y tal como se declara en la sentencia, porque la protección o el bienestar animal no aparece en la Constitución como un ámbito material específico de la acción de los poderes públicos [FJ 3]. Al conformar la protección animal una "política transversal", amparada por diversos títulos competenciales, estatales y autonómicos, se produce un entrecruzamiento o concurrencia de títulos habilitantes diferentes, que convierten las políticas públicas sobre protección animal en una materia muy amplia a la hora de ser encuadrada y examinada en términos constitucionales.

Llegamos ahora al punto más controvertido de la sentencia. El grupo parlamentario Popular del Senado cree que la Ley 6/2018 vulnera el principio de proporcionalidad en la finalidad de la ley, al imponer una ideología animalista que equipara peligrosamente la dignidad de la persona con la de los animales (10.1 $\mathrm{CE}$ ). La ley riojana pretendía garantizar el "máximo nivel de protección y bienestar" a los animales, pero este derecho a una protección máxima, alega la parte actora, solo corresponde a las personas, en función de la dignidad que les es intrínseca. De este modo, según el grupo recurrente, no puede hablarse de dignidad de los animales, ya que no está regulada como un valor constitucional, más allá de la referencia genérica a la protección del medio ambiente (art. 45 CE). A la postre, conduciría a relativizar la dignidad humana.

A tal efecto, el Tribunal Constitucional no aprecia equivalencia entre la dignidad humana y la protección y el bienestar de los animales, que es un bien de rango infraconstitucional, ni entiende que el propósito fuera relativizar, comprometer o preterir la dignidad de la persona ni los derechos inviolables que le son inherentes. El Tribunal se preocupa por recordar que su deber es de control 
jurídico, y no político, de oportunidad, calidad técnica o idoneidad y, por tanto, las intenciones políticas del autor de la ley no son objeto de su enjuiciamiento. Ello no le impide, no obstante, concluir el fundamento jurídico aclarando que:

"Procurar, a través de disposiciones normativas, que se dispense buen trato a los animales de compañía y que se eviten o minimicen, en lo posible, sufrimientos innecesarios, injustificados o evitables a los animales de producción en las actividades ganaderas y comerciales, son medidas legítimas que el legislador estatal y autonómico pueden adoptar en el marco de sus respectivas competencias que puedan proyectarse sobre esta materia y que no tienen por qué comprometer la dignidad inherente a la persona en modo alguno. Antes bien, la creciente preocupación por la protección de naturaleza, y en particular de los animales, constituye una tendencia generalizada en las sociedades más avanzadas, que es vista como una manifestación de progreso moral y como tal perfectamente acomodada a la dignidad del ser humano [FJ 11]."

Según la parte actora, también se vulnera la libertad ideológica y libertad religiosa (art. 16.1 CE), al imponer la ley riojana una convicción filosófica como creencia obligatoria a todos los ciudadanos, y el principio de prohibición de confesiones de carácter estatal (16.3 CE). En tal sentido, el Tribunal Constitucional entiende que de ninguna forma se estaría infringiendo precepto constitucional alguno, pues el art. 16.3. CE establece que "ninguna confesión tendrá carácter estatal", por lo que en cualquier caso la imposición de una ideología determinada sería solamente autonómica. Pero en cualquier caso, el TC no aprecia que los preceptos impugnados "perturben o impidan de algún modo la adopción o el mantenimiento en libertad de una determinada ideología o pensamiento" (SSTC 137/1990, FJ 8, y 177/2015, FJ 5; ATC 19/1992, de 27 de enero, FJ 2). Ni tampoco cabe entender que la Ley 6/2018 obligue a las personas poseedoras de animales en la Rioja a adherirse a un pretendido ideario animalista, sino que el legislador autonómico les establece unas obligaciones y prohibiciones con el fin de fomentar la tenencia responsable y evitar el maltrato animal.

Posteriormente, el Tribunal Constitucional entra a examinar la alegada vulneración del principio de legalidad en materia sancionadora (9.3. y 25.1 CE), porque según el grupo recurrente, las infracciones que establece la Ley 6/2018 
son indeterminadas. Por ejemplo, se alega que el concepto de maltrato no puede ser aplicado a todos los animales, porque se vulnerarían los principios de tipicidad y predeterminación de las infracciones administrativas, y de proporcionalidad, porque afectaría a todas las conductas con animales, como la producción de animales para la alimentación humana, ciertas prácticas veterinarias, la experimentación para fines científicos, la caza o la tauromaquia. El Tribunal Constitucional se remite al FJ 5, donde ya se resuelve que en la legislación estatal existen prácticas con animales que, aun pudiendo suponer para los animales algún tipo de sufrimiento o dolor, en ciertos casos son legítimas. Por lo tanto, se desestiman los artículos recurridos porque no incurren en vulneración del principio de legalidad sancionadora, ya que la tipificación del maltrato animal contenida sí "satisface la inexcusable exigencia de predeterminación normativa". En cuanto a la presunta violación del principio de proporcionalidad, el TC considera que el grupo recurrente no razona de qué modo se produciría tal infracción, por lo que rechaza la alegada vulneración.

Por otro lado, se alega el quebrantamiento de los principios de seguridad jurídica e interdicción de la arbitrariedad de los poderes públicos (art 9.3 CE), al ampliar el legislador riojano el objeto y ámbito de aplicación de la ley, y carecer de explicación racional algunos preceptos, no especificando qué animales quedan protegidos por la ley. No obstante, el Alto Tribunal, después de analizar cada artículo impugnado, considera que no concurre ninguna transgresión de los principios alegados, ya que el objetivo genérico que se proclama atañe a todo tipo de animales, si bien la exposición de motivos señala que va dirigida fundamentalmente a los animales de compañía y los que se encuentran bajo la responsabilidad de personas. Ello sin perjuicio de que determinados preceptos se refieran a otro tipo de animales. Otros artículos impugnados en este sentido no se entran a valorar, debido a la pérdida sobrevenida de objeto con la nueva redacción posterior a la ley riojana de medidas fiscales y administrativas para el año 2020.

Además, la parte recurrente alegaba la vulneración de la inviolabilidad del domicilio (18.2 CE), puesto que la ley riojana establece que los funcionarios pueden acceder libremente, sin previo aviso ni consentimiento, a todo lugar para comprobar el grado de cumplimiento de la ley. Una vez más, el Tribunal 
Constitucional, determina que la posible inviolabilidad del domicilio que se podría atentar queda descartada tras la reforma introducida por la Ley del Parlamento de la Rioja 2/2020. Ahora se especifica que solo es posible el acceso con una orden judicial, por lo que desestima la impugnación.

Por otro lado, la parte actora consideró que se atentaba la libertad de expresión y de producción y creación literaria y artística (art. 20.1.a) y b) CE), al prohibir y limitar, la ley riojana, el uso de animales para filmación de escenas de crueldad animal. EI TC entra a valorar si el artículo que regula este aspecto se podría considerar que introduce un supuesto de censura previa. Lo cierto es que el artículo, en realidad, requiere que la filmación que reproduzca escenas de sufrimiento de animales cuente con la autorización previa de la consejería competente en la materia, para garantizar que el daño sea simulado. Y entiende que solo se refiere a creaciones artísticas, y no a noticias ni retransmisiones por medios de difusión audiovisual de espectáculos autorizados, que se deben regir por su normativa específica —refiriéndose, efectivamente, a actividades cinegéticas o corridas de toros. Por lo tanto, no compromete la libertad de producción y creación artística y se desestima este motivo de inconstitucionalidad.

Ante todo lo expuesto, puede constatarse, una vez más, la visión antropocéntrica contenida en toda la legislación vigente española, y después de la interpretación del Tribunal Constitucional, también de la legislación autonómica que, efectivamente, debe ceñirse a la estatal. Tanto es así que la única y última finalidad de la existencia de los animales es, al parecer, el servicio al ser humano, ya sea en forma de compañía, de espectáculo o como bien de consumo y/o uso. En este sentido, la STC 81/2020, de 15 de julio, obliga a reflexionar sobre el concepto de la dignidad, y en concreto, la de los animales. El grupo parlamentario Popular del Senado parece tenerlo bastante claro: los animales no tienen dignidad. Su argumento es que si se aceptara, se estaría equiparando, y por consiguiente, relativizando e incluso despreciando la dignidad de la persona, que le es inherente. En este sentido, la imposición de la esterilización obligatoria para los animales de compañía (perros, gatos y hurones) resultó ser especialmente polémica. A pesar de estar razonado en evitar la superpoblación y el abandono animal, algunos sectores señalaron la norma como una falta a los 
derechos y libertades constitucionales. Del mismo modo, también resultó muy discutida la obligación de realizar al menos dos paseos diarios a los perros, porque "ni siquiera está previsto para los seres humanos"3. Parece, pues, que el trato a los animales conforme a su condición de seres sintientes, no acaba de ser compatible con las "necesidades" humanas.

Finalmente, y en otro sentido, merece ser comentado que, tal y como ocurriera en la Sentencia 176/2019, de 18 de diciembre, de nuevo se han formulado tres votos particulares en la sentencia que ahora se analiza. En ellos se reitera la discrepancia acerca de la denegación de la adhesión del Consejo de Gobierno de La Rioja al recurso de inconstitucionalidad. La mayoría del Tribunal fundamenta esta exclusión en la carencia de legitimación activa de los ejecutivos autonómicos para recurrir leyes aprobadas por la asamblea legislativa de sus propias comunidades autónomas (art. 32.2. LOTC). Tanto el magistrado don Juan Antonio Xiol Ríos como la magistrada doña María Luisa Balaguer Callejón se remiten a la ya citada STC 176/2019 para fundamentar su discrepancia. Por su parte, el magistrado Ricardo Enríquez Sancho defiende que, de conformidad al art. 34 LOTC, en este caso no hay una verdadera adhesión o intervención del gobierno autonómico y, por tanto, no debió inadmitirse tal adhesión. Ello es así porque en realidad, expone Enríquez, el Consejo de Gobierno de La Rioja aquí no es un tercer interviniente, sino "una parte necesaria en el proceso constitucional a la que el tribunal debe obligatoriamente emplazar", que formuló sus alegaciones sobre el recurso de inconstitucionalidad interpuesto por más de cincuenta miembros del grupo Popular del Senado. Además, añade Enríquez que, de conformidad con el art. 34 LOTC

(...) en sus alegaciones al recurso las partes comparecidas pueden exponer lo que estimen oportuno, sea a favor o en contra de la inconstitucionalidad pretendida, en el bien entendido de que si apoyan la inconstitucionalidad, como aquí sucede, ello no convierte a esos órganos en nuevos y autónomos recurrentes de modo que puedan pedir la anulación de preceptos diferentes de los que fueron objeto de recurso, ni les otorga un derecho separado a que "su" recurso sea resuelto mediante sentencia en caso de desistimiento

\footnotetext{
${ }^{3}$ Así se alega, por ejemplo, en el recurso de inconstitucionalidad núm. 1203-2019 que resulta objeto del presente análisis.
} 
del único y auténtico recurrente. Simplemente les otorga el derecho a que sus alegaciones sean admitidas y valoradas por el tribunal, otorgándoles el valor que merecen al ser formuladas por órganos con legitimidad democrática, funciones de dirección política y gobierno y una perspectiva singular y propia de la que carece este tribunal. Más allá de posibles intereses partidistas, no es baladí que el órgano de gobierno de una comunidad autónoma aprecie vicios de inconstitucionalidad y falta de competencia en una ley aprobada por su propio parlamento y ofrezca a este tribunal argumentos al respecto."

\section{LÍMITES A LA POTESTAD TRIBUTARIA AUTONÓMICA: PROHIBICIÓN DE DOBLE IMPOSICIÓN SOBRE EL MISMO HECHO IMPONIBLE}

La Sentencia del Tribunal Constitucional 84/2020, de 15 de julio, resuelve sobre el recurso de inconstitucionalidad interpuesto por el presidente del Gobierno contra el artículo único, apartado cuarto, de la Ley de las Cortes de Castilla y León 6/2018, de 13 de noviembre, por el que se modificaba el impuesto sobre la afección medioambiental causada por determinados aprovechamientos del agua embalsada, por los parques eólicos y por las instalaciones de transporte de energía eléctrica de alta tensión. Éste impuesto está regulado en el texto refundido de las disposiciones legales de la Comunidad de Castilla y León en materia de tributos propios y cedidos, aprobado mediante el Decreto Legislativo 1/2013, de 12 de septiembre.

De acuerdo con el promotor del recurso, la normativa castellanoleonesa incluía un nuevo hecho imponible sobre la afección medioambiental que sería sustancialmente igual al ya contenido en una norma estatal de carácter tributario: el previsto en el art. 15.I a) y b) de la Ley 15/2012, de 27 de diciembre, de medidas fiscales para la sostenibilidad energética. Esto es, se estaría contraviniendo la prohibición de doble imposición prevista en el art. 6.2 de la Ley Orgánica 8/1980, de 22 de septiembre, de financiación de las comunidades autónomas (LOFCA), que no permite que los tributos autonómicos recaigan sobre hechos imponibles ya gravados por el Estado.

La cuestión esencial de la sentencia reside, pues, en si existe o no una coincidencia entre el hecho imponible del tributo autonómico y el correspondiente 
al impuesto estatal. Es decir, se trata de averiguar si ambos impuestos son equivalentes. Para el examen de la cuestión, existe doctrina constitucional consolidada sobre los límites de la potestad tributaria de las comunidades autónomas. Así, el TC toma como parámetro las SSTC 74/2016, de 14 de abril y 43/2019, de 27 de marzo - ya analizadas en su momento en las correspondientes crónicas ${ }^{4}$ — en las que se había pronunciado sobre impuestos aparentemente análogos al supuesto aquí planteado. De manera similar a lo acordado en ambas sentencias, el juez de la constitucionalidad considera, para este caso, que existe una identidad de hechos imponibles entre el impuesto autonómico y el impuesto estatal. Para ello, el tribunal entra a examinar comparativamente todos los elementos esenciales de los dos tributos, a saber, el hecho imponible, los sujetos pasivos, los elementos de cuantificación y los fines de los impuestos.

Por un lado, el hecho imponible del tributo autonómico consiste en el "riesgo de alteración del medioambiente provocado por el combustible nuclear gastado y depositado con carácter temporal en las centrales nucleares situadas en el territorio de la Comunidad de Castilla y León" [art. $51.1 \mathrm{c}$ ) del texto refundido aprobado por el Decreto Legislativo 1/2013]. Por otro lado, los hechos imponibles del tributo estatal consisten en "la producción de combustible nuclear gastado resultante de cada reactor nuclear" y "la producción de residuos radioactivos resultantes de la generación de energía nucleoeléctrica”. De modo que la fundamentación del gravamen autonómico ya se encontraría subsumida dentro del impuesto estatal, según la parte actora.

Sostiene el recurrente que ambos tributos, estatal y autonómico, recaen sobre el mismo hecho: generar residuos en una central nuclear. Además, desde la misma perspectiva: ambos gravan las externalidades negativas que supone la energía nuclear, medidas por los riesgos que esta comporta. Resulta particularmente interesante la argumentación por la Junta de Castilla y León, quien presentó alegaciones en oposición a la demanda. Mientras que el recurso de inconstitucionalidad se basaba en la identidad de hechos imponibles, las

\footnotetext{
${ }^{4}$ A saber: Jordi Jaria-Manzano, "Jurisprudencia constitucional en materia de protección del medio ambiente (segundo semestre 2016)" en Revista Catalana de Dret Ambiental, 7(2), 2016 y "Jurisprudencia constitucional en materia de protección del medio ambiente (primer semestre 2019)" en Revista Catalana de Dret Ambiental, 10(1), 2019.
} 
alegaciones de la Junta castellanoleonesa se fundan en la consideración de que se trata de dos impuestos distintos, haciendo hincapié en que el autonómico es, a diferencia del estatal, un impuesto con fines extrafiscales. La intentio legis del impuesto estatal es crear una fuente de ingresos públicos con fines estrictamente fiscales, mientras que la del impuesto autonómico es compensar a la sociedad por las cargas ambientales derivadas del almacenamiento nuclear. El juez de la constitucionalidad, no obstante, da la razón al promotor del recurso, declarando la norma impugnada inconstitucional en base a la coincidencia del hecho imponible en los dos impuestos. Su argumentación es que "dado que todo combustible nuclear debe ser siempre almacenado, no tiene lógica, o resulta en todo caso artificioso, pretender que se pueda aislar el riesgo del depósito temporal con respecto del proceso productivo; uno y otro impuesto recaen sobre el mismo hecho imponible" [FJ 4.1].

Asimismo, el recurrente, a quien el TC da la razón, alega que los elementos esenciales son los mismos en los dos impuestos en comparación: tanto los sujetos pasivos (quienes exploten o realicen las actividades descritas en el hecho imponible), como las bases imponibles (los elementos combustibles nucleares gastados), como la finalidad extrafiscal (orientar los ingresos resultantes del impuesto a la preservación del medio ambiente / compensar a la sociedad por las cargas que debe soportar como consecuencia de la generación de residuos radioactivos). En consecuencia, el promotor del recurso defiende, por conexión o consecuencia, la inconstitucionalidad del resto de preceptos de la misma ley autonómica, dada su vinculación con el hecho imponible que se impugna. Preceptos que el TC estima también como inconstitucionales.

En cuanto al ámbito objetivo, para la Junta de Castilla y León es diferente la producción de energía eléctrica en una central nuclear (impuesto estatal), que la afectación medioambiental derivada del almacenamiento del combustible nuclear gastado (impuesto autonómico), siendo el proceso de almacenamiento una actividad distinta y separada, posterior a la fase de producción. Sin embargo, el TC da la razón al recurrente, y no a la Junta, pues no existe ningún supuesto en el cual el combustible nuclear no sea objeto de un almacenamiento específico posterior. Esto es, la fase de almacenaje es implícita, necesaria, en la producción del combustible nuclear. Por lo que, en realidad, el impuesto autonómico está 
gravando el combustible nuclear gastado, cosa que ya hace el gravamen estatal, dado que la generación de energía eléctrica dentro de una central nuclear es un proceso único.

En consecuencia, el Tribunal Constitucional declara la inconstitucionalidad del art. 51.1.c) del texto refundido autonómico en materia de tributos propios y cedidos (DL 1/2012, modificado por la Ley 6/2018), por vulnerar los arts. 133.2 CE (regulación de impuestos sólo de acuerdo con las Constitución y las leyes) y 157.3 CE (conflictos de competencias financieras entre Estado y CCAA), así como el citado art. 6.2 LOFCA. También hace extensiva la declaración de inconstitucionalidad al resto de preceptos del texto autonómico que se refieren específicamente al mismo gravamen sobre las centrales nucleares: el inciso "por las centrales nucleares" del capítulo I del título II y del art. 50.1, los arts. 50.4, 54.4 y 55.4 , y la disposición transitoria de la Ley 6/2018.

Ante esta interpretación restrictiva que hace el Tribunal Constitucional de la protección medioambiental, resulta de particular interés el voto particular emitido por el magistrado Juan Antonio Xiol Ríos. Igual que en el caso de las mencionadas SSTC 74/2016 y 43/2019, el juez manifiesta, una vez más, su discrepancia con la mayoría, dando por reproducidas las observaciones realizadas en el voto particular que formuló en las dos ocasiones anteriores. En ellas, pone de relieve lo que considera que es la configuración constitucional de la autonomía financiera de las comunidades autónomas, y la protección medioambiental como una finalidad extrafiscal constitucionalmente legítima y de primera magnitud en la configuración del poder tributario autonómico. Aquella discrepancia es la misma que le lleva ahora a sostener que la regulación del impuesto autonómico es plenamente respetuosa con la configuración constitucional del poder tributario estatal. Cosa que comportaría, en efecto, una protección más elevada del medio ambiente.

\section{COMPETENCIAS SOBRE MONTES: POTESTAD DE DESLINDE.}

La Sala de lo Contencioso-administrativo del Tribunal Superior de Justicia de Andalucía, planteó, en mayo de 2019, una cuestión de inconstitucionalidad en relación con el artículo 6.1 .3 de la Ley 2/1992, de 15 de junio, forestal de 
Andalucía. A la cuestión se adhirieron la fiscal general y el abogado del Estado. El precepto impugnado atribuía a la administración forestal autonómica la potestad de deslinde de montes públicos. Ello podía estar entrando en contradicción con la normativa estatal, el art. 21.1 de la Ley 43/2003, de 21 de noviembre, de montes - en adelante, LM - que reserva esta potestad a la administración titular del monte, para el caso concreto, el Ayuntamiento de Jaén.

En la Sentencia 96/2020, de 21 de julio, el Tribunal Constitucional califica la cuestión planteada de un supuesto de inconstitucionalidad mediata o indirecta, pues la posible infracción constitucional derivaría de la eventual contradicción con preceptos básicos, y no de la incompatibilidad directa con la Constitución. Para apreciar la inconstitucionalidad del precepto recurrido, el Tribunal primeramente comprueba, por un lado, que la norma estatal infringida por la ley autonómica sea una norma básica y dictada legítimamente al amparo del título competencial que la Constitución reserva al Estado. Esta naturaleza formal y materialmente básica resulta afirmativa, pues la ley estatal es la LM, regulada al amparo del art. 149.1.18 CE (bases del régimen jurídico de las administraciones públicas) y, por tanto, ajustada al orden constitucional de distribución de competencias.

Por otro lado, el Tribunal Constitucional comprueba que la contradicción sea "efectiva e insalvable por vía interpretativa", tal y como dicta la doctrina constitucional (por todas, STC 161/2019, de 12 de diciembre, FJ 6). En efecto, resulta ser así. La norma autonómica dispone que la administración pública que ha de ejercer la potestad de deslinde de montes es la Junta de Andalucía, mientras que la norma estatal establece que es la administración titular del monte. Además, la Ley forestal de Andalucía utiliza como criterio para catalogar los montes el de la titularidad, mientras que la Ley de Montes estatal utiliza el criterio de la utilidad pública. Esto implica que, mientras que la ley autonómica incluye en el catálogo todos los montes, sean de dominio público o patrimoniales, la ley básica no incluye todos los montes públicos, sino solo aquellos que contribuyan a la consecución de determinadas finalidades. Ante la imposibilidad de acomodar los preceptos impugnados al orden constitucional, el TC estima la nulidad parcial del precepto legal autonómico que atribuye a la Junta de Andalucía la potestad de deslinde respecto de montes públicos que no son de 
su titularidad; y extiende "por conexión o consecuencia", la declaración de inconstitucionalidad al precepto que faculta a la administración forestal andaluza para ejercer las potestades de investigación, recuperación de oficio y deslinde de todos los montes públicos.

Para apreciar la cuestión desde otra perspectiva, resultan particularmente interesantes las alegaciones que habían presentado contra el recurso la Junta y el Parlamento de Andalucía, en tanto que los preceptos estatal y autonómico en contraste admitían, según ellos, una interpretación integradora. De hecho, señalaron que la norma autonómica otorgaba un plus de tutela medioambiental. Este argumento no parece descabellado; la ley andaluza permitía complementar las previsiones básicas dirigidas a proteger los valores medioambientales y ecológicos que expresan los montes públicos, tanto como fuente de recursos naturales como ejerciendo de proveedores de múltiples servicios ambientales (protección del suelo y el ciclo hidrológico, fijación del carbono atmosférico, depósito de la biodiversidad, etc). La regulación andaluza establecía un régimen más extenso y completo de protección a los montes públicos, en el supuesto de que las administraciones titulares no pudieran ejercer las facultades de defensa de tales bienes. Por otro lado, la norma andaluza podía no estar impidiendo que las administraciones titulares de los montes públicos ejercieran sus potestades sobre sus bienes, sino más bien añadir la posibilidad de intervención autonómica.

\section{USO DE BOLSAS DE PLÁSTICO. PREVALENCIA DE COMPETENCIAS EN MEDIO AMBIENTE FRENTE A LA PLANIFICACIÓN ECONÓMICA.}

En la STC 100/2020, de 22 de julio, se enjuicia la constitucionalidad de los apartados 1.a) y 2 del art. 23 de la Ley Foral 14/2018, de 18 de junio, de residuos y su fiscalidad (Navarra), en virtud de los cuales se establecen limitaciones a la utilización de bolsas de plástico. Ya se puede avanzar que el recurso de inconstitucionalidad del cual deriva, interpuesto por el abogado del Estado en representación del presidente del Gobierno, queda desestimado. Los apartados que se evalúan por el Tribunal Constitucional habían sido impugnados por, supuestamente, incurrir en inconstitucionalidad mediata o indirecta, al vulnerar 
los arts. 2 y 4 del Real Decreto 293/2018, de 18 de mayo, sobre reducción del consumo de bolsas de plástico y por el que se crea el registro de productores. Este real decreto, alegaba el recurrente, había sido promulgado como normativa básica en virtud del art. 149.1.13 CE (bases y coordinación de la planificación general de la actividad económica). Una vez más, el Tribunal Constitucional aplica la metodología de los dos requisitos para apreciar si existe un supuesto de inconstitucionalidad mediata. El primero, que la norma estatal que se considera infringida por la ley autonómica sea básica, tanto en un sentido formal como material. El segundo requisito, que la contradicción sea efectiva e insalvable por vía interpretativa.

El Tribunal Constitucional subraya que

"el art. 149.1.13 CE exige una lectura restrictiva, puesto que una excesivamente amplia podría constreñir e incluso vaciar las competencias sectoriales legítimas de las comunidades autónomas (SSTC 29/1986, FJ 4, y 141/2014, FJ 5)". (...) Asimismo, es doctrina de este tribunal que no toda medida que incida en la actividad económica puede incardinarse en este título. Para ello es preciso, como se ha indicado, que tenga 'una incidencia directa y significativa sobre la actividad económica general, pues de no ser así se vaciaría de contenido una materia y un título competencial más específico' (SSTC 21/1999, de 25 de febrero, FJ 5, y 141/2014, FJ 5)".

Tal y como defienden la letrada de la Comunidad Foral de Navarra y el letrado del Parlamento de Navarra en sus alegaciones, el título competencial concurrente más especifico sería la protección del medio ambiente. Justifican que el art. 23 de la Ley Foral impugnado se enmarca dentro de la legítima competencia de la Comunidad Foral de Navarra en desarrollo legislativo y ejecución en materia de medio ambiente y ecología (art. 57.c) LORAFNA5), respetando la legislación básica estatal sobre medio ambiente (149.1.23 CE). De hecho, el juez de la constitucionalidad expone que dispensar una adicional y mayor protección ambiental no es inconstitucional, recordando que

"lo básico, como propio de la competencia estatal en esta materia, cumple más bien una función de ordenación mediante mínimos que han de

\footnotetext{
${ }^{5}$ Ley Orgánica 13/1982, de 10 de agosto, de Reintegración y Amejoramiento del Régimen Foral de Navarra.
} 
respetarse en todo caso, pero que pueden permitir que las comunidades autónomas con competencias en la materia establezcan niveles de protección más altos (SSTC 101/2005, de 20 de abril, FJ 5, y 15/2018, de 22 de febrero, FJ 5, entre otras muchas). De acuerdo con la jurisprudencia constitucional, lo genérico o lo detallado, lo abstracto o lo concreto de cada norma no es el criterio decisivo para calificar como básica una norma de protección del medio ambiente, sino su propia finalidad tuitiva [SSTC 102/1995, FJ 9, y 69/2013, de 14 de marzo, FJ 6 b)].

Para determinar cuál es el título competencial prevalente, el Tribunal realiza un ejercicio de ponderación de los títulos en disputa. Expone que tanto la Ley estatal como la autonómica que regulan la limitación de las bolsas de plástico se adoptan en el marco de las normas de la Unión Europea y se transponen por el Estado en el ordenamiento interno con el objetivo de hacer frente a los problemas ambientales que generan los residuos de las bolsas de plástico. Es decir, para proteger el medio ambiente.

Por consiguiente, el TC considera que los apartados enjuiciados no se enmarcan en el ámbito de la competencia estatal en materia de ordenación de la actividad económica, pues no tienen una incidencia directa ni significativa sobre la actividad económica general, ni tienen por objeto establecer una regulación uniforme que garantice el mercado único. De modo que el Real Decreto 293/2018, sobre reducción del consumo de bolsas de plástico no tiene entidad suficiente para ocasionar una distorsión sustancial en el funcionamiento del mercado y, de hecho, no hace ninguna referencia a las finalidades económicas que le atribuye la representación del Estado.

En efecto, las medidas adoptadas frente a las bolsas de plástico tienen como finalidad primordial disuadir al consumidor del uso de este tipo de bolsas y conseguir así reducir los efectos negativos que estas causan al medio ambiente. Y si las comunidades autónomas deciden adoptar normas adicionales con niveles más altos de protección, sin colisionar con otros valores constitucionales, no debería suponer ningún problema, sino al contrario, resultar una medida bien recibida e incluso, ejemplar para otras comunidades autónomas. En Navarra, pues, la Ley Foral 14/2018, de 18 de junio, de residuos y su fiscalidad, sigue íntegramente vigente. Las bolsas de plástico no compostables, 
independientemente de su gramaje, están efectivamente prohibidas en esta Comunidad foral desde enero de 2020, adelantándose así al Estado, donde su prohibición será efectiva a partir de enero de 2021. 